\title{
The influence of coupling agents on mechanical properties of lignin-filled polypropylene composites
}

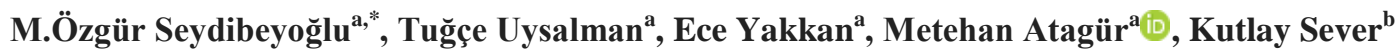

\begin{abstract}
Natural fiber filled/reinforced composite materials are heavily studied in the academy and industry. Lignin is both a natural filling material and a side product of cellulosic bioethanol and paper industries. Lignin has been used as a filling/reinforcing material for twenty years in order to create value-added products. In this study, $10 \%$ wt. soda lignin reinforced polypropylene composites with and without coupling agents was produced by using twin-screw extruder in order to investigate the effect of coupling agent type and the effect of coupling agent content $(0.1 \%, 0.3 \%$, and $0.5 \%$ wt.). Mechanical, thermal and morphological properties of the composites were investigated. The results showed that the optimum amount of coupling agents in composites was $0.3 \%$ for the best interaction with lignin and polymer. According to TGA analysis, it can be concluded that lignin filled composite is more stable compared to neat copolymer.
\end{abstract}

Keywords: Lignin, Polypropylene, Mechanical properties, Thermal properties

\section{Lignin polipropilen kompozitlerinde ara yüzey kimyasallarının mukavemete etkisi}

Özet: Doğal elyaf ile takviye edilen kompozit malzemeler akademide ve endüstride yoğun çalışılan bir konudur. Lignin doğal bir dolgu maddesi olarak kullanılmasının yanı sıra selüloz esaslı biyoetanol ve kağıt endüstrilerinin de yan ürünüdür. Lignin çok farklı uygulamalarda 20 yıla yakındır kullanılmaktadır. Bu çalışmada soda lignin ve polipropilen kompozitleri çift vidalı polimer işleme makinasında karıştırılmışıı ve 2 farklı ara yüzey ajanı da $\% 0.1, \% 0.3$ ve $\% 0.5$ oranlarında karıştırılmıştır. Mekanik özellikler, 1sıl özellikler ve morfolojik etkileri incelenmiştir. Sonuçlar göstermiştir ki en iyi sonuçlar \% 0.3 yüzey kimyasal oranı ile yapılmıştır. Termogravimetrik analizler lignin katkılı polipropilen kompozitlerinin 1sıl kararlılığının daha yüksek olduğunu göstermiş̧ir.

Anahtar kelimeler: Lignin, Polipropilen, Mekanik özellikler, Isıl özellikler

\section{Introduction}

A strong interest in the use of renewable resources for energy and material production is increasing day by day because of different reasons mainly economic, modest investments and human impacts on the environment (Luong et al. 2012). Use of renewable sources such as sun, wind, hydropower, and biomass for energy and materials have been seen the solution of global problems such as climate change, environmental pollution and security of supply of fossil fuels (De Wild et al. 2012). This growing interest about a green and sustainable chemistry has also contributed to call attention to biomass and specifically on lignocellulosic feedstock as a promising, renewable and vast resource for chemicals (Laurichesse and Averous 2014). Lignocellulosic biomass can be used as renewable feedstock for the co-production of materials, energy, chemicals, and fuels via integral bio-refinery concepts(De Wild et al. 2012).

As a lignocellulosic biomass, lignin has called attention and was started to use in different areas. Among these areas, interest in the development of lignin-containing polymeric materials has been upheld more or less continuously for the past 20 years (Fan et al. 2011; González Sánchez and Alvarez 1999; Kadla and Kubo 2004; Kharade and Kale 1999; Košíková et al. 1995; Li et al. 2011; Li et al. 1997; Mariotti et al. 2013; Olsson et al. 2011; Sailaja and Deepthi 2010). The study made by Peng et al., (2014) wood flour, lignin and cellulose were chosen to blend with polypropylene (PP) matrix at different loading levels to evaluate the influence of accelerated ultra violet weathering. It is found that the presence of high lignin content caused an acceleration in the discoloration of composites. Moreover, lignin filled composites gave less loss of flexural strength, modulus and cracks (Peng et al. 2014). Zhong et al., (2011) fabricated PP blend with $70 \mathrm{wt} \%$ lignin content. According to tensile and flexural test, if lignin content increases, modulus and strength values decreases. The impact strength was enhanced by blending up to $40 \mathrm{wt} \%$ alkylated lignin. SEM images has showed that alkylated lignin is homogeneously dispersed in the PP. TGA analysis showed that high lignin content improved the thermal stability (Zhong et al. 2011). The aim of paper made by Pouteau et

\footnotetext{
$凶$ a Materials Science and Engineering, Izmir Katip Celebi University, İzmir, Turkey

b Mechanical Engineering, Izmir Katip Celebi University, İzmir, Turkey

@ * Corresponding author (İletișim yazarı): seydibey@ gmail.com

$\checkmark \quad$ Received (Gelis tarihi): 01.03.2018, Accepted (Kabul tarihi): 11.09.2018
}

Citation (Atıf): Seydibeyoğlu, M.Ö., Uysalman, T., Yakkan, E., Atagür, M., Sever, K., 2018. The influence of coupling agents on mechanical properties of lignin-filled polypropylene composites. Turkish Journal of Forestry, 19(3): 308-316. DOI: $10.18182 /$ tjf.399787 
al. (2004) is to investigate good polymer candidates displaying good compatibility with Kraft lignin. It was found that only low molecular weight lignins were compatible with apolar and very polar matrices (Pouteau et al. 2004). Toriz et al. (2002) studied lignin filled (between 10 wt. $\%$ and 60 wt. \%) polypropylene composites by blending. Tensile and flexural strength were reduced and it was seen a spectacular decrease in un-notched Izod impact strength compared with the properties of neat polypropylene, although Young's modulus and flexural modulus were improved. It was concluded that maleic anhydride grafted polypropylene (MAPP) as a coupling agent improved strength properties (Toriz et al. 2002).

The purpose of this study is the production and characterization of lignin filled polypropylene composites for industrial applications by using different coupling agents in order to decrease the interface mismatch between lignin and polypropylene.

\section{Material and methods}

\subsection{Materials}

Protobind 2400 was provided as a gift by GreenValue SA Company. Heterophasic polypropylene copolymer Moplen $2000 \mathrm{HEXP}\left(\mathrm{Tm}=165^{\circ} \mathrm{C}, \rho=0.9 \mathrm{~g} / \mathrm{cm}^{3}\right.$, Melt flow rate $\left.\left(230^{\circ} \mathrm{C} / 2.16 \mathrm{~kg}\right)=16 \mathrm{~g} / 10 \mathrm{~min}\right)$ produced by Lyondell Basell Company, was used as the polymeric material. PG1190 (POSS) and the commercial coupling agent FUSABOND ${ }^{\circledR}$ E265 (FUSE) were used as a coupling agent.

\subsection{Preparation of the materials for extrusion process}

Copolymer was grinded by using micronized device with $1400 \mathrm{rpm}$ speed during 15 minutes in order to decrease the particle size of the pellets. Lignin and copolymer were mixed for five minutes until observing the proper mixing in order to produce composites without coupling agent. Lignin and copolymer were mixed with POSS and FUSE respectively with the compositions $0.1 \%, 0.3 \%$ and $0.5 \%$ (by weight) when composites with coupling agent was produced.

\subsection{Extrusion process}

Lignin filled composites with and without coupling agents were manufactured by using twin-screw extruder (corotate) branded Labtech. The prepared mixture was placed to the hopper of extruder and feed with $20 \mathrm{rpm}$. Zone temperatures of extruder were selected between the temperatures $170^{\circ} \mathrm{C}$ and $185^{\circ} \mathrm{C}$. Screw speed is adjusted as $190 \mathrm{rpm}$. The extruded strand was passed through a water bath and granulated. The granules were dried at $80 \pm 2{ }^{\circ} \mathrm{C}$ for $1 \mathrm{~h}$ to remove any moisture. Table 1 shows produced composites and their sample codes.
Table 1. Produced composites and their samples codes

\begin{tabular}{cc}
\hline Composites & Sample codes \\
\hline Copolymer & cPP \\
10\% Lignin & cPP10L \\
10\% Lignin-0.1\% FUSE & cPP10L-0.1F \\
10\% Lignin-0.3\% FUSE & cPP10L-0.3F \\
10\% Lignin-0.5\% FUSE & cPP10L-0.5F \\
10\%Lignin-0.1\% POSS & cPP10L-0.1P \\
10\% Lignin-0.3\%POSS & cPP10L-0.3P \\
$10 \%$ Lignin-0.5\% POSS & cPP10L-0.5P \\
\hline
\end{tabular}

\subsection{Thermokinetic mixer}

Melt mixing of the pellets was achieved using a Gelimat, a high-speed laboratory thermokinetic mixer. Composite samples of $50 \mathrm{~g}$ were mixed for 15-20 seconds at2000 rpm in order to get mixture in the form of dough.

\subsection{Fabrication of composite plate}

After heating the hot press until processing temperature $\left(200^{\circ} \mathrm{C}\right)$, produced composite pellets were placed into the mold cavity $(15 \mathrm{~cm} \times 15 \mathrm{~cm})$ between Teflon sheets which were used to avoid direct contact of PP composites with the hot press metal platens during heating and pressing. Plates were obtained from the mixture by using Hydraulic Laboratory Press (Labtech) with heating and cooling plates. Samples were pressed under 40 bar pressure at $200^{\circ} \mathrm{C}$ for 20 seconds and pressed under 120 bar pressure at $20{ }^{\circ} \mathrm{C}$ for 2 minutes.

\subsection{Fourier transform infrared (FTIR) analysis}

Copolymer, lignin and their composites prepared with FUSE and POSS were investigated with FTIR analysis. Thermo Scientific ${ }^{\mathrm{TM}}$ FTIR spectrometer in Attenuated Total Reflection Infrared (ATR-IR) mode was used to obtain the spectra of lignin and lignin composites. Attenuated total reflection infrared (ATR-IR) spectra of the materials were collected at a resolution of $4 \mathrm{~cm}-1$ with a range of 400-4000 $\mathrm{cm}^{-1}$ and a number of 16 scans per sample. Spectral outputs were recorded in transmittance mode as a function of wave number.

\subsection{TGA analysis}

Thermogravimetric analysis (TGA) was carried with Perkin Elmer STA 8000 TG/DTA by heating from room temperature by $10^{\circ} \mathrm{C} / \mathrm{min}$ to $700^{\circ} \mathrm{C}$ under $\mathrm{N}_{2}$ atmosphere.

\subsection{Tensile testing}

Tensile testing samples were obtained by using a mold which cut the plate with blades according to the American Society for Testing and Materials (ASTM) D638 standard. SHIMADZU AGS-X 5kN tensile test machine was used for lignin reinforced composites at room temperature with a crosshead speed of $50 \mathrm{~mm} / \mathrm{min}$. 6 specimens were tested for each composite formulation to obtain a reliable average of tensile properties as well as their corresponding standard deviations. Young's modulus (E, deduced from the initial slope of the strength-strain curve), the strength $\left(\sigma_{\max }\right)$ and the elongation at break are evaluated. 


\subsection{Dynamic mechanical analysis (DMA)}

The storage modulus and $\tan \delta$ of neat PP and its composites were evaluated using a DMA Q800 (TA Instruments Inc., USA). Single cantilever was used and multi frequency-strain modulus mode was selected to test all specimens between the temperatures $30^{\circ} \mathrm{C}$ and $120^{\circ} \mathrm{C}$ in air atmosphere.

\subsection{Scanning electron microscopy (SEM) analysis}

TESCAN VEGA3 SEM device was used to observe the microstructure of lignin, copolymer and polymer composites. SEM images were taken from the fracture surfaces of the tensile specimens. The samples were coated with gold and the images and accelerated voltage was adjusted as $30 \mathrm{kV}$ and images were taken at different magnifications.

\section{Results and discussion}

\subsection{FTIR analysis}

Figure 1 shows that the FTIR spectra of copolymer, lignin, coupling agent and their composites modified with FUSE between the wave numbers $4000 \mathrm{~cm}^{-1}$ and $500 \mathrm{~cm}^{-1}$. FTIR spectra of lignin showed that lignin had peaks at 3351 , 2941 and $2879 \mathrm{~cm}^{-1}$. The peak at $3351 \mathrm{~cm}-1$ is H-bonded O$\mathrm{H}$ stretch. In the study made by Yeo et al. (2015), the hydroxyl groups was selected among the various functional groups. Because the hydroxyl groups as functional organic moiety on the lignin surface are the reactive sites and change the polarity of lignin surface that can hinder their dispersion in hydrophobic polymer matrices (Yeo et al. 2015). Also, the peaks at 2941 and $2879 \mathrm{~cm}^{-1}$ are attributed to the $\mathrm{C}-\mathrm{H}$ stretch. One of the important peaks is to mention is the band at $3351 \mathrm{~cm}^{-1}$ which become invisible in all lignin filled composites. Copolymer had peaks which represented C-H stretching at 2949, 2916, 2866 and $2837 \mathrm{~cm}^{-1}$ and also $1375 \mathrm{~cm}^{-1}$ and $1358 \mathrm{~cm}^{-1}$. The peak at $1375 \mathrm{~cm}^{-1}$ is syringyl group and the peak at $1358 \mathrm{~cm}^{-1}$ is the $\mathrm{C}-\mathrm{H}_{3}$ bonding and $\mathrm{C}$ $\mathrm{O}$ stretch. Composites have these peaks like copolymer. But, it is seen that addition of lignin to copolymer makes a decrease in the intensity of these peaks. Also, there was a decrease in the intensity of copolymer peaks at $1375 \mathrm{~cm}^{-1}$ and $1358 \mathrm{~cm}^{-1}$ due to addition of lignin in all composites spectra. Lignin had the peaks at $1595 \mathrm{~cm}^{-1}$ which is aromatic functionality, aromatic $\mathrm{C}=\mathrm{C}$ stretching, $1513 \mathrm{~cm}^{-1}$ which is aromatic skeletal vibration (Sahoo et al. 2011b). FTIR spectra showed that these peaks came from lignin became visible in its composites. Lignin also gave a peak at 1211 $\mathrm{cm}^{-1}$ which represented $\mathrm{C}-\mathrm{O}-\mathrm{C}$ soft segments. It was considered that the peak at $1247 \mathrm{~cm}^{-1}$ observed in the spectrum of the composite sample comes from the lignin peak at $1211 \mathrm{~cm}^{-1}$.

Figure 2 shows the FTIR spectra of copolymer, lignin, coupling agent and their composites modified with POSS. The peak of lignin at $3351 \mathrm{~cm}^{-1}$ became invisible in all composites. But, the addition of lignin to copolymer made a decrease in the intensity of the peaks at 2949, 2916, 2866 and $2837 \mathrm{~cm}^{-1}$. The peak of lignin at $1681 \mathrm{~cm}^{-1}$ which his $\mathrm{C}=\mathrm{O}$ stretch became visible in all composites. Also, the peaks of lignin at $1595 \mathrm{~cm}^{-1}$ and $1513 \mathrm{~cm}^{-1}$ became visible in all composites. Copolymer had the peak at $1453 \mathrm{~cm}^{-1}$ which is $\mathrm{C}-\mathrm{H}$ deformation. Lignin had peak at $1455 \mathrm{~cm}^{-1}$ which also represented $\mathrm{C}-\mathrm{H}$ deformation. There was a decrease in the intensity of the peaks of the composites when these two peaks come together. Also, there is a decrease in the intensity of copolymer peaks at $1375 \mathrm{~cm}^{-1}$ and $1358 \mathrm{~cm}^{-1}$ due to addition of lignin in all composites spectra. Compared with \%10lignin filled composite which had no modification, C-O-C soft segment peak at $1211 \mathrm{~cm}^{-1}$ could be seen only in all composites modified with POSS, especially in the composite modified with $0.5 \%$ POSS with higher intensity.

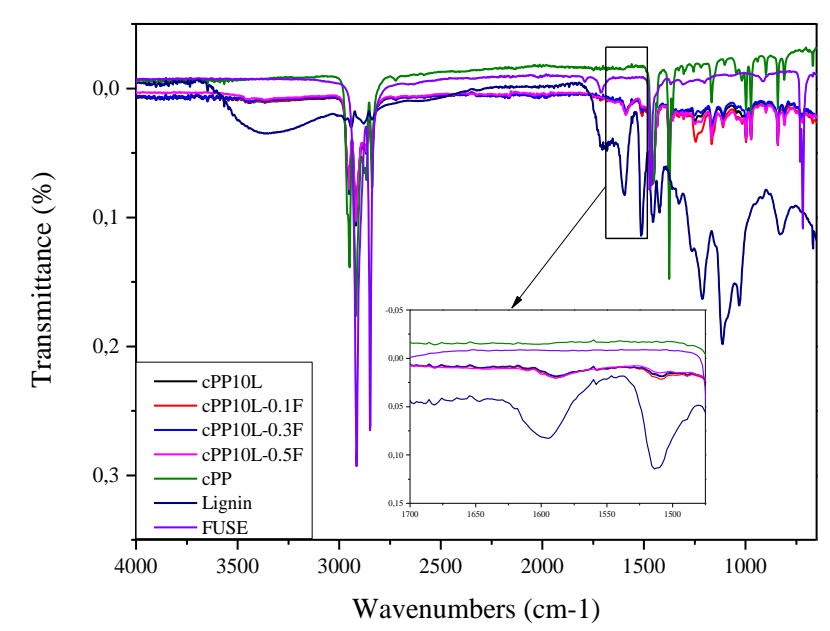

Figure 1. FTIR spectra of copolymer, lignin, coupling agent and their composites modified with FUSE

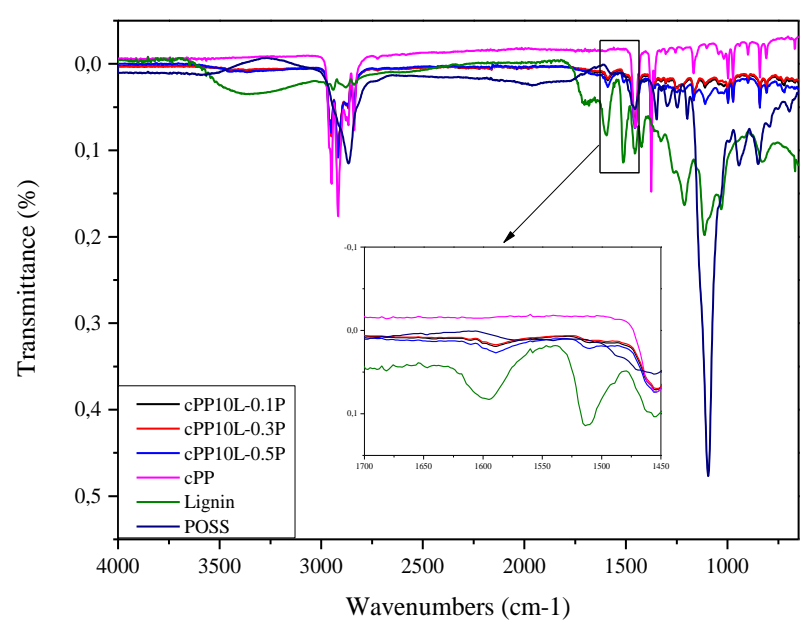

Figure 2. FTIR spectra of copolymer, lignin, coupling agent and their composites modified with POSS 


\subsection{TGA analysis}

Table 2 shows onset temperature, degraded weight, end temperature and charred residues of lignin, extruded neat copolymer and all composites.

In TGA curve of lignin, which is showed in Figure 3, it was seen that initial weight loss around $2.3 \%$ wt. occurs at $49.3{ }^{\circ} \mathrm{C}$ and continues until the temperature $75.3{ }^{\circ} \mathrm{C}$.

The reason of this weight loss could be attributed to loss of moisture from lignin. The study (Sahoo et al. 2011a) found the similar result as well. Weight loss at the onset temperature explained as the degradation correspond to the scission of weak ether bonds present in lignin inter units (bO-4 linkage) in this study. Main degradation of lignin was observed at $286{ }^{\circ} \mathrm{C}$ and $57.1 \%$ wt. is lost and this degradation continues until the temperature around $430{ }^{\circ} \mathrm{C}$.

Table 2. Onset temperature, degraded weight, end temperature and Maximum Degradation Temperature of the specimens

\begin{tabular}{ccccc}
\hline Specimens & $\begin{array}{c}\mathrm{T}_{\text {onset }} \\
\left({ }^{\circ} \mathrm{C}\right)\end{array}$ & $\begin{array}{c}\text { Weight Loss } \\
(\%)\end{array}$ & $\begin{array}{c}\mathrm{T}_{\text {end }} \\
\left({ }^{\circ} \mathrm{C}\right)\end{array}$ & $\begin{array}{c}\text { Charred } \\
\text { residues at } \\
600^{\circ} \mathrm{C}(\%)\end{array}$ \\
\hline Lignin & 286.0 & 57.1 & 429.9 & 42.9 \\
cPP & 443.1 & 97.7 & 472.8 & 2.3 \\
cPP10L & 438.9 & 93.1 & 477.1 & 6.9 \\
cPP10L-0.1F & 439.8 & 89.0 & 477.4 & 11 \\
cPP10L-0.3F & 439.7 & 91.5 & 478.1 & 8.5 \\
cPP10L-0.5F & 438.7 & 92.3 & 477.3 & 7.7 \\
cPP10L-0.1P & 441.3 & 91.9 & 478.9 & 8.1 \\
cPP10L-0.3P & 439.3 & 90.4 & 476.9 & 9.6 \\
cPP10L-0.5P & 430.2 & 89.4 & 476.3 & 10.6 \\
\hline
\end{tabular}

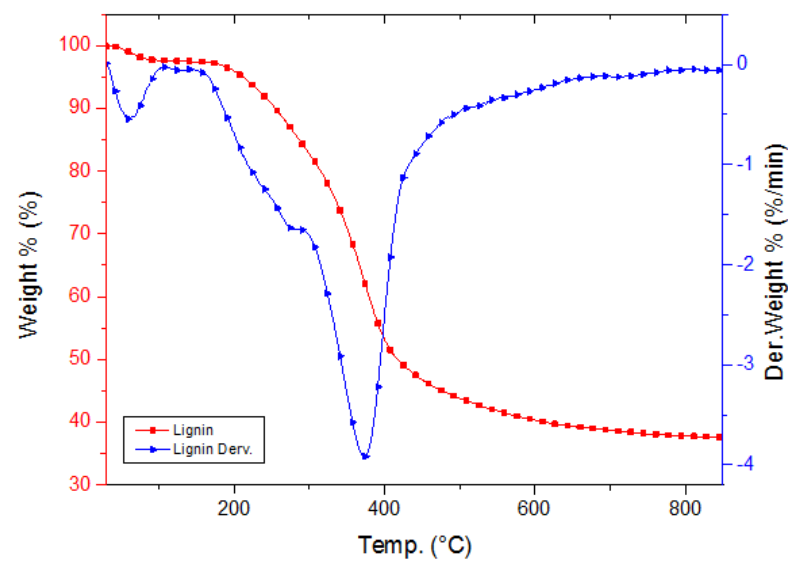

Figure 3. TGA curve of lignin
Pyrolytic degradation of lignin was explained in the study (Sun and Tomkinson 2001)as involved fragmentation of inter-unit linkages, releasing monomeric phenols into the vapor phase. Practically, extruder barrel temperatures were set between $170{ }^{\circ} \mathrm{C}$ and $185{ }^{\circ} \mathrm{C}$ for the production of lignin filled composites. According to $\mathrm{TG}$ curve, the onset degradation temperature of lignin is $286{ }^{\circ} \mathrm{C}$ and lignin lost $3 \%$ wt. of its weight between these temperature ranges. In TGA analysis of lignin, the charred residue was found around $43 \%$. The result is similar to the literature which concluded that the non-volatile residue at $600{ }^{\circ} \mathrm{C}$ was large, amounting to $45.5 \%$ of the lignin material (Sun and Tomkinson 2001) and it explains the reason based on the structure of lignin which reflected a high degree of branching and substantial condensation of the lignin preparations.

According to the TG curve, copolymer degraded between the temperatures around $443.1^{\circ} \mathrm{C}$ and $472.8^{\circ} \mathrm{C}$. Copolymer lost $97.7 \%$ wt. between these temperature ranges. When TGA analysis data of the composites produced was investigated, it was seen that when copolymer was filled with $10 \%$ wt. lignin, the composite started to degrade around $439^{\circ} \mathrm{C}$. It means that addition of lignin increases the onset temperature and could be concluded that makes the composite more stable compared to copolymer itself. The addition of lignin to copolymer without modification decreased the weight loss percentage approximately $6 \%$. There was no significant difference in onset temperatures which was around $439^{\circ} \mathrm{C}$ between the composites modified with FUSE when compared with the $10 \%$ wt. lignin filled composites. It means FUSE has no effect on onset temperature. On the other hand, addition of $0.1 \%$ POSS increased the onset temperature approximately $3^{\circ} \mathrm{C}$ when compared with the composite without coupling agent. By increasing the POSS content of the composites, onset temperature decreased.

When FUSE concentration increased, the degraded weight of the composites slightly increased. On the other hand, when POSS concentration increased, the degraded weight of the composites slightly decreased. End temperature of the composites was approximately the same with each other but higher than the temperature of copolymer which is $474.8^{\circ} \mathrm{C}$.

\subsection{Tensile testing}

Tensile test results of neat copolymer and lignin composites with and without coupling agent are shown in Table 3. Standard deviations were in an acceptable range for all samples.

Table 3. Elongation at break, Young's Modulus and tensile strength data of copolymer and the composites

\begin{tabular}{cccc}
\hline Samples & Elongation at break $(\%)$ & Young's modulus (MPa) & Tensile strength (MPa) \\
\hline cPP & $43.5 \pm 3.809$ & $583.3 \pm 13.94$ & $744.4 \pm 13.641$ \\
cPP10L & $17.5 \pm 2.092$ & $740.2 \pm 13.603$ & $13.88 \pm 2.150$ \\
cPP10L-0.1F & $33.8 \pm 2.095$ & $723 \pm 15.524$ & $13.132 \pm 1.879$ \\
cPP10L-0.3F & $34.4 \pm 2.931$ & $722 \pm 15.513$ & $14.978 \pm 1.869$ \\
cPP10L-0.5F & $27 \pm 2.999$ & $677 \pm 15.022$ & $13.8525 \pm 2.148$ \\
cPP10L-0.1P & $23.6 \pm 2.803$ & $672.6 \pm 12.967$ & $13.56 \pm 2.126$ \\
cPP10L-0.3P & $42.8 \pm 3.271$ & $652.8 \pm 12.774$ & $13.48 \pm 1.835$ \\
cPP10L-0.5P & $40.5 \pm 3.182$ & $13.702 \pm 1.850$ & \\
\hline
\end{tabular}


Figure 4 shows tensile strength and elongation at break graph of copolymer and lignin filled composites. When the data was analyzed, it was seen that tensile strength of $10 \%$ lignin filled composite is almost the same with copolymer. Without using any coupling agents, only the addition of lignin had no minute effect on tensile strength. This outcome was attributed to the weak interfacial adhesion between the hydrophilic filler and the hydrophobic polymer matrix. (Sahoo et al. 2011b).

For the composites produced with FUSE coupling agent, it was thought that maleic anhydride graft in the structure of FUSE coupling agent could ensure an improvement in the tensile properties but significant differences could not be observed between values of copolymer and composites containing FUSE. The reason of that was explained the literature (Yeo et al. 2015);MAPP is one of a compatibilizer for lignocellulosic-polymer composites due to the interaction through chemical bonds between the pendant anhydride of MAPP and hydroxyl group of lignin, which would form ester linkages in the melt-mixed composites. However, the ester bonds between MAPP and lignin were too few to improve their mechanical properties compared with those of neat $\mathrm{cPP}$.

Among the composites produced with FUSE coupling agent, the highest tensile strength is belong to $0.3 \%$ FUSE added composite. Although the tensile strength of the composite prepared with $0.1 \%$ FUSE addition is higher than copolymer's strength, it is lower than the composite coupled with $0.3 \%$ FUSE. Tensile strength of the composite produced with $0.5 \%$ FUSE is almost the same with copolymer, it has lower strength comparing with $0.3 \%$ FUSE added composite.

These results were also supported by the data of the SEM images of the samples. The reason of being higher strength of $10 \%$ lignin filled composite compared with the composite containing $0.1 \%$ FUSE is thought that because less voids in the structure in $0.1 \%$ FUSE added composite. Also, it was seen that in SEM images, the voids decreased with the contribution of $0.3 \%$ FUSE to the structure compared with the sample coupled with $0.1 \%$ FUSE addition.

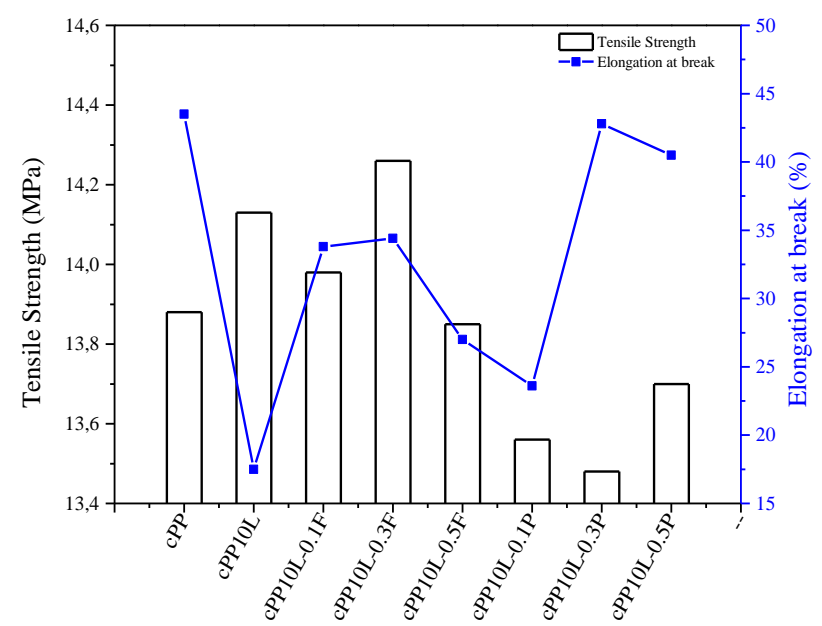

Figure 4. Tensile strength and elongation at break graph of copolymer and lignin filled composites
Similar trends in tensile properties of composite containing POSS was reported as there is no significant differences observed between values of copolymer and composites with POSS coupling agent. $0.1 \%$ POSS, $0.3 \%$ POSS and $0.5 \%$ POSS added composites have tensile strength values $13.56 \mathrm{MPa}, 13.48 \mathrm{MPa}$ and $13.70 \mathrm{MPa}$, respectively.

When the elongation at break data of copolymer and all composites is investigated, large variability in \% elongation was observed. It was found that addition of lignin to neat copolymer made a decrease of $60 \%$ in elongation at break values of copolymer which has $43.5 \%$. The cause of this decline was explained as due to the mismatch between the polymer matrix interfaces with lignin particles(Sahoo et al. 2011a). Elongation at break value, which shows a significant decrease with the addition of $10 \%$ lignin to neat copolymer, had improved with the use of FUSE and POSS coupling agents. When the elongation at break values of composites containing FUSE coupling agent, it was observed that the highest value was belong to $0.3 \%$ FUSE added composite. Elongation at break value of the composite containing $0.1 \%$ FUSE is very close to value of $0.3 \%$ FUSE containing composite. But the increase of FUSE addition to $0.5 \%$ deteriorated the elongation at break value and it was observed a decrease of about $22 \%$ comparing with $0.3 \%$ FUSE added composite.

When it was investigated the elongation at break values of the composites containing POSS coupling agent, the composite containing $0.3 \%$ POSS has the closet elongation at break value ( $42.8 \%)$ to copolymer's value $(43.5 \%) .0 .1$ $\%$ POSS content in lignin composite improved \%strain of lignin filled composite but it could not be as good as $0.3 \%$ POSS addition. It was seen that $\%$ strain value could not be improved with the $0.5 \%$ POSS addition to lignin filled composite, on the contrary a decline was observed in comparison with $0.3 \%$ POSS used composite. Elongation at break values are concerned, the optimum POSS amount in composites could be selected as $0.3 \%$ for the best interaction with lignin and polymer.

Young's modulus of copolymer was found as 583.30 $\mathrm{MPa}$. It was observed that $10 \%$ wt. lignin addition to neat copolymer made an increase of $28 \%$ in Young's modulus of copolymer itself. The improvement in the properties of lignin filled composites could be indicated an interaction, possibly polar-polar interaction between lignin and polyolefin matrix. It is determined that not only Young's Modulus of $10 \%$ lignin added composite but also all composites produced with coupling agents are quite higher than the modulus value of copolymer.

This significant increase in Young's modulus and decreasing of elongation at break with lignin addition indicates that stiffer material obtained. The composite filled $10 \%$ lignin without any coupling agents has the highest Young's Modulus value as $744.40 \mathrm{MPa}$. In the composites produced with FUSE coupling agent, it was seen a decrease in Young's modulus while increasing FUSE content in the composites. This decrease is about $6 \%$ with the addition of $0.1 \%$ FUSE and about $3.1 \%$ with the addition of $0.3 \%$ and $0.5 \%$ FUSE added composites when comparing with $10 \%$ lignin filled composite. This result was interpreted in the study made by Pucciariello et al.(2004) as; As far as the 
modulus is concerned, it generally increases, after the addition of lignin (Pucciariello et al. 2004).

\subsection{DMA analysis}

DMA analysis was performed between the temperatures $30^{\circ} \mathrm{C}$ and $100^{\circ} \mathrm{C}$ in order to investigate the viscoelastic behavior and the impact of the modification with coupling agents on lignin-matrix adhesion. Dynamic mechanical analysis helps to understand the mechanical performance of the materials with regards to change in frequency and temperature. It measures storage modulus which gives information about stiffness of the material and damping which is a measure of how well the material absorbs energy. Damping measurement called as Tan $\delta$ which is the ratio of loss modulus over storage modulus (Seydibeyoğlu 2012).

The storage modulus of neat copolymer decreases when the temperature increases. The same result was found in the study made by (Sahoo et al. 2011a) and explained as "The reduction of storage modulus with temperature can be attributed to the softening of the polymer due to the increase in the chain mobility of the polymer matrix at high temperatures". This interesting result was observed with the addition of $10 \%$ wt. lignin without modification to copolymer, the storage modulus of neat copolymer decreased throughout the whole temperature scale. That means lignin incorporation decreases the stiffness of the material. Also, the results showed that the storage modulus values of the lignin composites modified with FUSE and POSS at their each compositions showed a decreasing trend between the temperatures $30^{\circ} \mathrm{C}$ and $100^{\circ} \mathrm{C}$. The results showed that the deformation of composites increases as the temperature increases.

As it is seen in Figure 5, when the storage modulus values of lignin filled composites modified with FUSE coupling agent were investigated at $30^{\circ} \mathrm{C}$, it is seen that $0.1 \%$ wt. FUSE addition to $10 \%$ wt. lignin filled composite made a decrease in storage modulus of $10 \%$ wt. lignin filled composite. Then the increasing content of FUSE amount to $0.3 \%$ made another decrease in the storage values of the composites. This decreasing trend ended with the addition of $0.5 \%$ wt. FUSE to the structure and storage values of composites increased again. This interesting result could be observed for other temperatures as well with the same trend.

Figure 6 shows the storage modulus of copolymer and its composites modified with POSS coupling agent. At 30 ${ }^{\circ} \mathrm{C}$, the addition of $0.1 \%$ wt. POSS to the structure of 10 $\%$ wt. lignin filled composite decreases the storage modulus of the composite but it has been observed that POSS coupling agent had adverse effects for other temperatures and it was observed an increase in the storage modulus.

The results were different from the FUSE added composites in terms of the increasing and decreasing trends. When the Table 3. is investigated, it is seen that storage modulus decreased with the increasing POSS amounts in the composites modified with POSS at $30^{\circ} \mathrm{C}$. Contrary to this, the result differs at the temperatures $50^{\circ} \mathrm{C}$ and $70^{\circ} \mathrm{C}$. At these two temperatures, storage modulus increased with the increasing POSS amount in the composite structures. At $100^{\circ} \mathrm{C}$, whereas storage modulus of composite material included $0.1 \%$ wt. POSS was $358.28 \mathrm{MPa}$, with the increasing POSS amount, storage modulus of composite material included $0.3 \%$ POSS was found as $361.96 \mathrm{MPa}$.
This interesting trend didn't valid for the composite incorporated with $0.5 \% \mathrm{wt}$. POSS, it is seen that the storage modulus of $0.5 \%$ wt. POSS composite was less than the storage modulus of composite modified with $0.1 \%$.

As the test data starts from room temperature, the glass transition temperature was not observed at these temperature scales. This is also reflected in Tan $\delta$ values as well. Lignin reinforced composites modified with FUSE and POSS coupling agents showed a broad single damping curve. The damping behavior was explained in the study made by (Pouteau et al. 2004) as "It is measured by the magnitude of $\tan \mathrm{d}$ since it is the ratio of loss modulus to storage modulus or energy dissipated to energy stored during a dynamic loading cycle."

According to this result, dissimilar observation could be reported as lignin filling may help the molecular mobility of copolymer matrix. Hereby, Tan $\delta$ increased since there is reduced inter friction between molecular chains. This interesting effect of lignin filling observed also in the composites throughout the whole temperature scale. Only the composite sample modified with $0.5 \%$ POSS was different as its Tan $\delta$ has a decreasing trend after $100^{\circ} \mathrm{C}$.

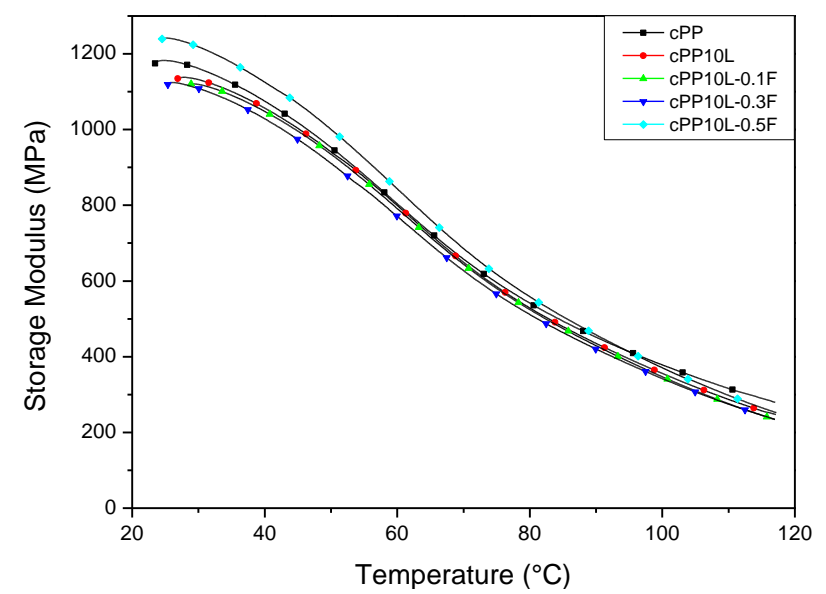

Figure 5. Storage modulus of FUSE composites

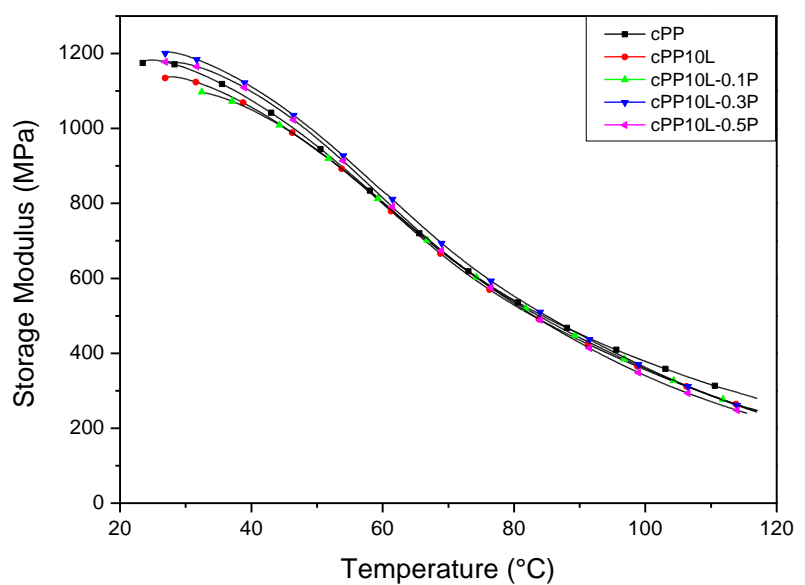

Figure 6. Storage Modulus of POSS composites 


\subsection{SEM analysis}

Figure 7 shows that the SEM images of copolymer, lignin and composites. SEM analysis has been performed by imaging the fracture surfaces of the tensile specimens of lignin filled composites. In the Figure 7 (a), air gaps were observed in copolymer surface. The reason of air voids within the structure could be explained as copolymer was not subjected to drying process prior to extrusion, and therefore the copolymer would absorb moisture from the air. In the typical SEM micrographs of lignin which is seen in Figure 7 (b), also it can be observed in fact that lignin has not homogeneous in size. The particle size of lignin changes between 5-35 $\mu \mathrm{m}$. When the SEM images of composites with and without modification was analyzed, it was considered that the gaps in SEM images of $10 \%$ wt. lignin composite without modification and composite modified with $0.1 \%$ wt. with FUSE and POSS cause due to interface mismatch between lignin and polymer matrix interface. In the composites modified with FUSE, it was observed that the number of gaps decreased in composites modified with
$0.3 \%$ and $0.5 \%$ concentration. In the composites modified with POSS, the number of gaps decreased in composites modified with $0.5 \%$ concentration. As a result, it was concluded that coupling agent had an improvement in composites compared with the $10 \%$ wt. lignin filled composite without modification.

\subsection{Application of optimized coupling agent content for automotive parts}

The optimized formulation was produced in large scale and the optimized composition was in injection molded to obtain an automotive part (Figure 8). One of the most important outcome was to be used by a commercial company, namely Farplas Auto Spare Parts Production Company in their product portfolio. For future studies, the use of side product lignin from paper industries and cellulosic bioethanol industries will create an important sustainable material from renewable resources. This study will also help increased usage of the bio based materials in industrial applications.

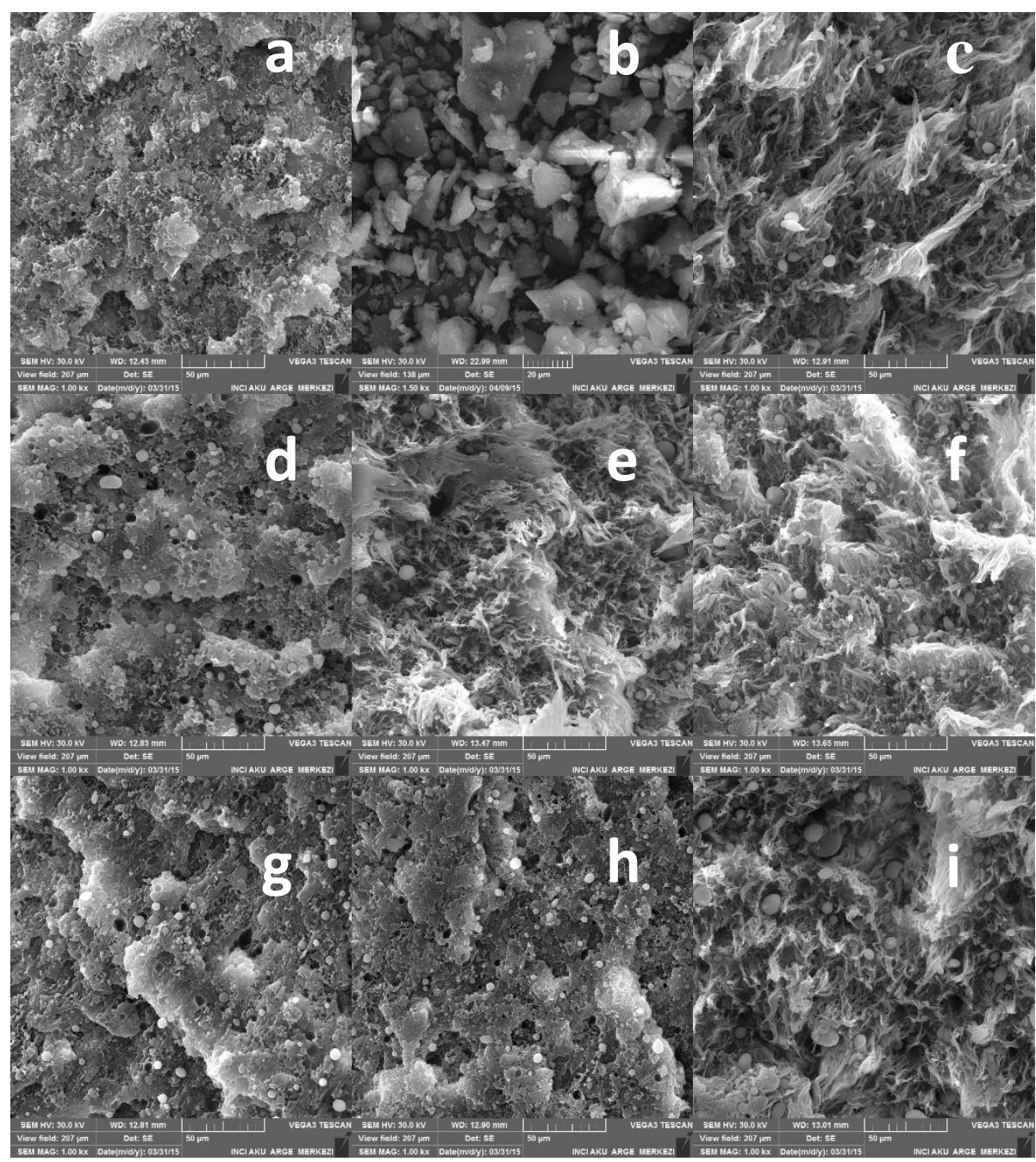

Figure 7. SEM images; a) cPP, b) Lignin c) cPP10L, d) cPP10L-0.1F, e) cPP10L-0.3F, f) cPP10L-0.5F, g) cPP10L-0.1P, h) cPP10L-0.3P, i) cPP10L-0.5P 


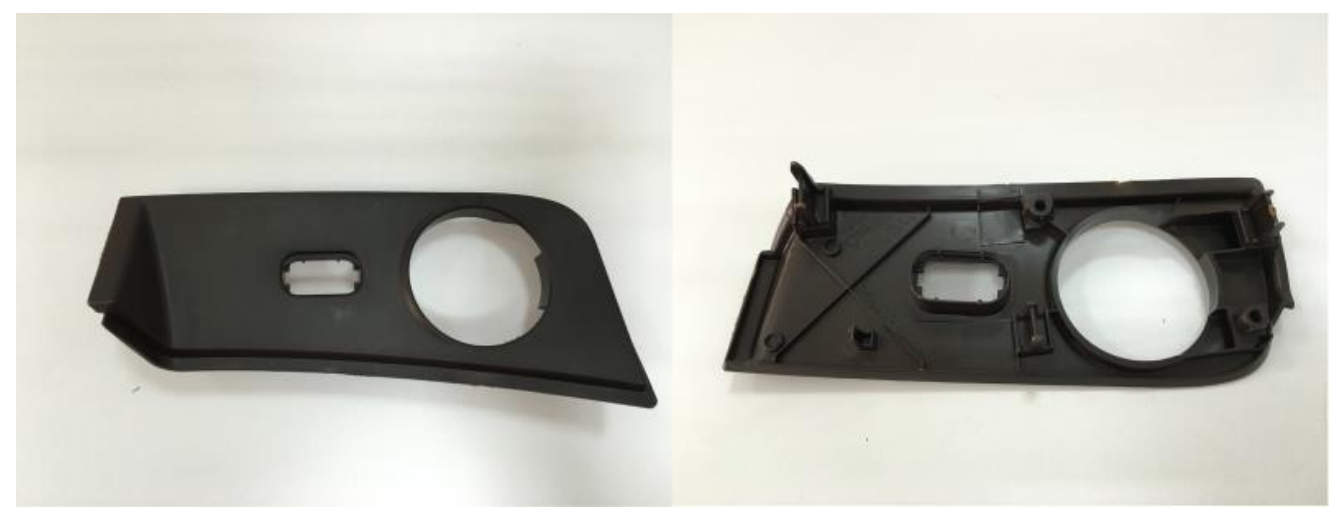

Figure 8. Final products of lignin filled PP composites

\section{Conclusion}

This is a very critical study on the utilization of lignin materials for the manufacturing of eco-friendly polymeric materials. In this study, we could achieve a new formulation being low-cost and environment friendly by using lignin. The processing conditions for preparing lignin based composites are optimized with mechanical properties improvement. Furthermore, it was shown that these materials can be used in certain automotive applications.

To conclude, lignin which is a side product of paper and cellulose based bioethanol industry has been utilized in polymeric materials creating an important value and this study will help the use of lignin in various polymer studies.

\section{Acknowledgement}

2013-STZ-161 project is greatly acknowledged for the study. 2016-ÖNP-MÜM-0002 project is also acknowledged.

\section{References}

De Wild, P., Huijgen, W., and Heeres, H. 2012. Pyrolysis of wheat straw-derived organosolv lignin. Journal of Analytical and Applied Pyrolysis 93: 95-103.

Fan, D., Chang, P.R., LING, N., Yu, J., and Huang, J. 2011. Structure and properties of alkaline lignin-filled poly (butylene succinate) plastics.

González Sánchez, C. and Alvarez, L. 1999. Micromechanics of lignin/polypropylene composites suitable for industrial applications. Macromolecular Materials and Engineering 272(1): 65-70.

Kadla, J.F. and Kubo, S. 2004. Lignin-based polymer blends: analysis of intermolecular interactions in ligninsynthetic polymer blends. Composites Part A: Applied Science and Manufacturing 35(3): 395-400.

Kharade, A. and Kale, D. 1999. Lignin-filled polyolefins. Journal of applied polymer science 72(10): 1321-1326.

Košíková, B., Revajová, A., and Demianova, V. 1995. The effect of adding lignin on modification of surface properties of polypropylene. European polymer journal 31(10): 953-956.

Laurichesse, S. and Averous, L. 2014. Chemical modification of lignins: Towards biobased polymers. Progress in Polymer Science 39(7): 1266-1290.
Li, J., Li, S., Wang, H., Yang, Y., and Guo, G. 2011. PREPARATION OF A LIGNIN-BASED COMPOSITE AND ITS PROPERTIES. 2011. No. 2.

Li, Y., Mlynar, J., and Sarkanen, S. 1997. The first 85\% kraft lignin-based thermoplastics. Journal of Polymer Science Part B: Polymer Physics 35(12): 1899-1910.

Luong, N.D., Binh, N.T.T., Kim, D.O., Kim, D.-S., Lee, S.H., Kim, B.J., Lee, Y.S., and Nam, J.-D. 2012. An eco-friendly and efficient route of lignin extraction from black liquor and a lignin-based copolyester synthesis. Polymer bulletin 68(3): 879-890.

Mariotti, N., Wang, X.M., Rodrigue, D., and Stevanovic, T. 2013. Combination of esterified kraft lignin and MAPE as coupling agent for bark/HDPE composites. Journal of Materials Science Research 3(2): 8.

Olsson, S., Ostmark, E., Ibach, R.E., Clemons, C.M., Segerholm, K., and Englund, F. The use of esterified lignin for synthesis of durable composites. In Proceedings of the 7th Meeting of the Nordic-Baltic Network in Wood Material Science and Engineering (WSE), Oslo, Norway. 2011. pp. 173-178.

Peng, Y., Liu, R., Cao, J., and Chen, Y. 2014. Effects of UV weathering on surface properties of polypropylene composites reinforced with wood flour, lignin, and cellulose. Applied Surface Science 317: 385-392.

Pouteau, C., Baumberger, S., Cathala, B., and Dole, P. 2004. Lignin-polymer blends: evaluation of compatibility by image analysis. Comptes rendus biologies 327(9-10): 935-943.

Pucciariello, R., Villani, V., Bonini, C., D'Auria, M., and Vetere, T. 2004. Physical properties of straw ligninbased polymer blends. Polymer 45(12): 4159-4169.

Sahoo, S., Misra, M., and Mohanty, A.K. 2011a. Enhanced properties of lignin-based biodegradable polymer composites using injection moulding process. Composites Part A: Applied Science and Manufacturing 42(11): 1710-1718.

Sahoo, S., Seydibeyoğlu, M., Mohanty, A., and Misra, M. 2011b. Characterization of industrial lignins for their utilization in future value added applications. Biomass and bioenergy 35(10): 4230-4237.

Sailaja, R. and Deepthi, M. 2010. Mechanical and thermal properties of compatibilized composites of polyethylene and esterified lignin. Materials \& Design 31(9): 43694379 . 
Seydibeyoğlu, M.Ö. 2012. A novel partially biobased PANlignin blend as a potential carbon fiber precursor. BioMed Research International 2012.

Sun, R. and Tomkinson, J. 2001. Fractional separation and physico-chemical analysis of lignins from the black liquor of oil palm trunk fibre pulping. Separation and $\begin{array}{lll}\text { Purification } & \text { Technology } & \text { 529-539. }\end{array}$ doi:https://doi.org/10.1016/S1383-5866(01)00153-8.

Toriz, G., Denes, F., and Young, R. 2002. Ligninpolypropylene composites. Part 1: Composites from unmodified lignin and polypropylene. Polymer Composites 23(5): 806-813.
Yeo, J.-S., Seong, D.-W., and Hwang, S.-H. 2015. Chemical surface modification of lignin particle and its application as filler in the polypropylene composites. Journal of Industrial and Engineering Chemistry 31: 80-85.

Zhong, M., Dai, H., Yao, H., Yang, J., and Chen, F. 2011. Strong, flexible high-lignin polypropylene blends. Polym Res Online. doi 10. 